Çukurova Üniversitesi Mühendislik Mimarlık Fakültesi Dergisi, 30(2), 55-64 ss., Aralık 2015

Çukurova University Journal of the Faculty of Engineering and Architecture, 30(2), pp. 55-64, December2015

\title{
Fakılar Boksit Cevher Özellikleri ve Potansiyeline ait ilk Bulgular (Çamlıyayla/Mersin)
}

\author{
Nil YAPICI ${ }^{* 1}$, Hakan GÜNEYLI'², Hatice KARAKILÇIK ${ }^{2}$ \\ ${ }^{1}$ Çukurova Üniversitesi, Mühendislik-Mimarlık Fak.,Maden Mühendisliği Bölümü, Adana \\ ${ }^{2}$ Çukurova Üniversitesi, Mühendislik-Mimarlık Fak.,Jeoloji Mühendisliği Bölümü, Adana
}

Geliş tarihi: 24.08 .2015

Kabul tarihi: 25.12 .2015

\section{Özet}

Türkiye'nin en önemli boksit cevherleşmeleri Orta Torosların Bolkardağları bölgesinde bulunmaktadır. $\mathrm{Bu}$ çalışma Mersin'in Çamlıyayla/Fakılar Köyü mevkiinde yeni bir boksit cevher yatağının ekonomik olarak öneminin değerlendirilmesi amacı ile yapılmıştır.

Cevherleşme, Bajosiyen-Santoniyen (Jura-Kretase) yaşlı kireçtaşı-dolomitik kireçtaşları içerisinde yarı düzenli-düzensiz olarak yataklanmıştır. Yapılan mineralojik ve XRD analizleri sonuçlarına göre; diyasporit, hematit, limonit, götit, lepidokrosit, rutil, kaolin mineralleri içeren karstik tip çoğunlukla oolitik-pizolitik yapılı boksitlerdir. Kimyasal içerikleri \%70-62 $\mathrm{Al}_{2} \mathrm{O}_{3}, \% 8,53-1,46 \mathrm{SiO}_{2}, \% 15,12-10,66$ $\mathrm{Fe}_{2} \mathrm{O}_{3}, \% 2,87-2,44 \mathrm{TiO}_{2}$ olarak tespit edilmiştir. İçerikleri bölgenin sektörel anlamda yeterli alüminyum zenginleşmesine sahip olduğunu göstermektedir. Arazide, AGİ marka 8 kanallı 84 elektrotlu cihaz ile çok elektrodlu rezistivite ve IP çalışmaları 3 profilde yapılmıştır. 540 metre uzunluğunda olan profillerde elektrod aralığı 20 metre alınarak dipole-gradient açılımı kullanılmıştır. Araziden elde edilen ölçüm verileri 'EartImager 2B ve 3B' programında değerlendirilmiş ve yeraltı yapı kesitleri elde edilmiştir. Bu kesitlerde Rezistivite ve IP ölçümlerinin birbirlerini desteklediği görülmüştür. IP kesitlerinde yüksek şarjabilite değerinin elde edilmesi, çalışma sahanında boksit madeninin varlığı yönünden olumlu olarak değerlendirilmiştir. Rezistivite kesitlerinde düşük rezistivite değerleri yüzeye yakın alanlarda tespit edilmiştir. Buna göre olası boksit rezervleri, düşük rezistivite ve yüksek şarjıbilite değeri veren yerlerdir.

Elde edilen veriler sonucu sadece 3 kesit için ortalama 120.000-150.000 ton'luk bir rezerv söz konusudur. Daha fazla profil analizlerinde bu miktarın çok daha fazla olduğu tahmin edilmektedir.

Anahtar kelimeler: Boksit, Çok elektrodlu rezistivite, IP yöntemi, Fakılar, Çamlıyayla-Mersin

\footnotetext{
* Yazışmaların yapılacağı yazar: Nil YAPICI, Çukurova Üniversitesi, İnşaat Mühendisliği Maden Mühendisliği Bölümü,,Adana, nyapici@cu.edu.tr
} 


\title{
Preliminary Findings of Ore Properties and Potential of Fakılar Bauxite (Çamlıyayla/Mersin)
}

\begin{abstract}
The Bolkardağı region of Central Taurides is host to a number of bauxite deposits of Turkey. This study focuses on the assessment of economic importance of a new bauxite deposits outcropped Çamlıyayla/Fakılar area in Mersin.

The ore deposits were regularly-semiregularly placed in limestone-dolomitic imestones (TriassicJurassic). According to mineralogical studies and XRD analyses, the bauxite samples are ooliticpysolithic, and have a main mineralogical content of diasporite, hematite, limonite, goethite, lepidocrocite, rutile and kaolinite. The main chemical compounds of the ores are $\mathrm{Al}_{2} \mathrm{O}_{3}(70-62 \%), \mathrm{Fe}_{2} \mathrm{O}_{3}$ $(15,12-10,66 \%), \mathrm{SiO}_{2}(8,53-1,46 \%)$ and $\mathrm{TiO}_{2}(2,87-2,44 \%)$. Composition of ore deposits sectorally indicate that the region has an adequate aluminum potential. At the terrain, multi-electrode resistivity and IP studies were performed in three profiles with equipment the AGI brand 8-channel and 84-electrode by taking electrode spacing of 20 meters at the profiles in length of 540 meters, dipole-gradient expansions are used. The obtained measurements data from the field are evaluated in 'Eartımag 2D and 3D' software and upon them underground structure cross section are prepared. Resistivity and IP measurements in these sections observed support each other. Obtaining high chargeability values in IP sections are evaluated positively for the presence of bauxite mine. Low resistivity values in resistivity sections are determined in the areas close to the surface. Accordingly probable reserves of bauxite ore are located at the places with low resistivity values and high chargeability.

The results show to be an average reserves of 120.000-150.000 tons for only three seismic sections. It is thought that this amount of reserve can probably emerged to be much greater in case of further more profile analysis.
\end{abstract}

Keywords: Bauxite, Multi-electrode resistivity, IP method, Fakılar, Çamlıyayla-Mersin

\section{GİRiş}

Alüminyum oksit ve hidroksitlerin bir karışımı olan boksit, alüminyum metali üretiminde kullanılan başlıca cevher olması bakımından dünya ticaretinde önemli yer almaktadır. Diyasporit $\left(\mathrm{Al}_{2} \mathrm{O}_{3} \cdot \mathrm{H}_{2} \mathrm{O}\right)$, böhmit $[\mathrm{AlO}(\mathrm{OH})]$, gibsit (hidrarjilit) $\left[\mathrm{Al}(\mathrm{OH})_{3}\right]$ minerallerinin bir karışımı olarak silis, demir oksitler ve $\mathrm{TiO}_{2}$ içermektedir. Sınıflandırılmalarında mineralojisi, oluşumu ve endüstriyel kullanım alanları dikkate alınmaktadır. Minerolojik yapılarına göre 3 grupta incelenir.

- Gibsitik boksitler (Trihidratik): Püskürük kayaçlardaki feldispat ve korundun düşük sicaklıklarda dekompozisyonu ile oluşur.

- Böhmitik boksitler (Monohidratik): Gibsitin dehidratasyonu sirasında bir ara ürün olarak ortaya çıkmışlardır.

Diyasporitik boksitler (Monohidratik): Yüksek sıcaklıklarda oluşmaktadırlar.

Oluşum şartlarına göre, 2 gruba ayrılmaktadırlar.

- Silikat boksitler: Alüminyumca zengin silikat kayaçlarının aşınması ve yıkanması sonucu meydana gelmektedirler.

- Karstik boksitler; Kireçtaşı ve dolomitlerin karstik boşluklarında oluşmaktadırlar.

Endüstriyel olarak sınıflandırmalar ise kullanım amaçlarına göre yapılmaktadır [1].

Boksit, kimyasal bileşimine bağlı olarak \% 85-90’1 metalurji sanayinde alümina ve alüminyum üretiminde tüketilmektedir. Kullanım alanına göre 
spesifikasyonlar Çizelge 1'de verilmiştir.

Çizelge 1. Boksitin sektörlere göre kimyasal içerikleri [1].

\begin{tabular}{|c|c|c|c|c|c|}
\hline $\begin{array}{c}\text { İçerik } \\
(\%)\end{array}$ & Metalurji & Kimyasal & Çimento & Refrakter & Aş̧ındırıcı \\
\hline $\mathrm{Al}_{2} \mathrm{O}_{3}$ & $50-55$ & Min.55 & $45-55$ & 84,5 & $80-88$ \\
\hline $\mathrm{SiO}_{2}$ & 0,15 & $5-18$ & Max.6 & 7,5 & $4-8$ \\
\hline $\mathrm{Fe}_{2} \mathrm{O}_{3}$ & $5-30$ & Max.2 & $20-30$ & 2,5 & $2-5$ \\
\hline $\mathrm{TiO}_{2}$ & $0-6$ & 3 & 3 & 4 & $2-5$ \\
\hline
\end{tabular}

Türkiye boksit yatakları çoğunlukla güneyde ve batıdan doğuya uzanan bir kuşak içinde bulunmaktadırlar. Bunların en önemlileri Konya/Seydişehir, Akseki, Zonguldak (Kokaksu), Mersin (Ayranc1), Adana (Saimbeyli), Muğla (Milas), Hatay (Payas), Gaziantep (İslahiye), Antalya (Alanya), Isparta (Yalvaç) olarak sıralanabilir (1). Çoğunu karst (lateritik) tipi böhmitik, diasporitik demirli boksitler oluşturmaktadır. Kokaksu yatağı (Zonguldak) hariç tamamı (\%95'i) Toros kuşağında bulunmaktadır [1]. Bu çalışma, Toros kuşağında bulunan boksit yataklarına yeni cevher rezervi eklenmesi ve ekonomiye katkısının incelenmesi amacı ile yürütülmüştür. Araştırma bölgesi Çamlıyayla/Fakılar Köyü/Mersin bölgesi Kozan N33-d2 paftası içerisinde bulunmaktadır (Şekil 1).

\section{METOD}

Çalışma alanı mineralojisi çalışmaları için sistematik cevher ve anakayaç örneğinde XRD, kimyasal analizleri (Kanada/ACME) ve mikroskop çalışmaları yürütülmüştür. Ayrıca bölgede AGI R8 marka çok kanallı rezistivite aleti ile, 3 adet profil boyunca elektrot 20 metre aralıkla dizilerek jeofizik rezistivite yöntemlerinden DipoleGradient (Rezistivite) ve IP tekniğinde ölçü alınmıştır. Profil uzunluğu 540 metre olmuştur. Alınan kayitlar EartImager 2D ve 3D

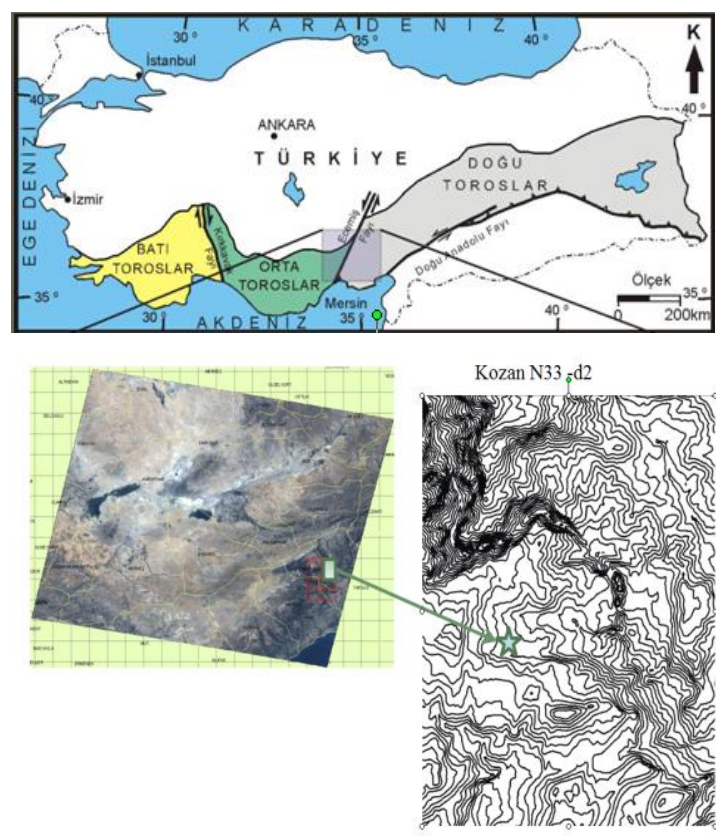

Şekil 1. Çalışma alanı yer bulduru haritası

programında değerlendirilerek yer altı yapı kesiti ortaya çıkartılmıştır.

\section{BÖLGESEL JEOLOJI}

Bölgede daha önce yapılan jeoloji etütlerinde Ünlügenç, [2] Paraotokton konumlu birimleri; Permo-Karbonifer yaşlı Karahamzauşağı formasyonu, Mesozoyik yaşlı Demirkazık kireçtaşı ile Yavça formasyonunun otokton konumlu Tersiyer yaşlı birimlerin ise sırasıyla; OligosenAlt Miyosen yaşlı Gildirli formasyonu, Alt Miyosen yaşlı Kaplankaya formasyonu ve OrtaÜst Miyosen yaşlı Karaisalı kireçtaşı olduğunu belirtmiştir.

Keniş [3], Jura-Kretase yaşlı; Demirkazık kireçtaşı, Üst Kretase yaşlı; Kızıldağ Melanjı ve Mersin Ofiyoliti, Oligosen-Alt Miyosen yaşlı; Gildirli formasyonu, Alt Miyosen yaşli; Kaplankaya formasyonu, Alt-Orta Miyosen yaşli; Karaisalı kireçtaşı ile Kuvaterner yaşlı; Alüvyon olmak üzere toplam 7 birim ayırtlamıştır. 
Ekingen [4], Çamlıyayla bölgesinde yaptığı çalışmalarda stratigrafik detay açıklamalar yaparak formasyonlar arası geçiş özelliklerini açıklamıştır.

Orta Torosların Bolkardağı bölgesinde yer alan boksit cevherleşmesi, Jura-Kretase yaşlı Bajosiyen-Santoniyen aralığında oluşmuş temel birimi karakterize eden kireçtaş1-dolomitik kireçtaşı, içerisinde yataklanmıştır. Birim, Demirkazık formasyonu olarak ele alınacaktır.

Yetiş [5] tarafından adlandırılan Demirkazık formasyonu, tabanında ayrışmış yüzeyi; kırmızımsı kahve renkli, taze kırık yüzeyi; gri-açık gri renkli, orta-kalın katmanlı, oldukça kıvrımlı bir yapıya sahip, içerisinde metamorfik çakıllar gözlenen, Alt Jura yaşlı kireçtaşları ile başlayan ayrışmış yüzeyi; gri-koyu gri renkli, taze kırık yüzeyi; gri-açık gri renkli, orta-kalın tabakalı, yer yer masif görünümlü, bol kırık ve çatlaklı (çatlaklar arası iri kalsit dolgulu), $\mathrm{H}_{2} \mathrm{~S}$ kokusu ve şekerimsi dokusu ile karakteristik dolomitler ile devam eden ve daha üst seviyelere çıkıldıkça dolomit miktarı azalan, dolomitik kireçtaşı, kireçtaşı birimlerinden oluşmaktadır.

Çalışma alanında tabanda Kaplankaya formasyonu ile uyumsuz, tavanda ise Alt-Orta Miyosen yaşlı Karaisalı formasyonu ile yanal ve düşey geçişli olarak gözlenmektedir (Şekil 2-3).

\section{BOKSITT CEVHERLEŞMELERİ}

Bolkardağ birliği içerisinde yer alan cevherleşmeler, Bajosiyen-Santoniyen (JuraKretase) yaşlı kireçtaşı-dolomitik kireçtaşları içerisinde yarı düzenli-düzensiz olarak yataklanmışlardır (Şekil 3).

Cevherleşmeler kireçtaşı doğrultusuna paralel olarak yüzlek vermektedir. Al-lateritleşmenin karstik tip modeline uygun kireçtaşları içerisinde bulunan boksitler pizolitik yapıda oluşmuştur (Şekil 4). Üst zonlarında demir alterasyonu gelişmiştir. Sahadaki yarma çalışmalarından alınan numunelerin parlak kesit örneklerinde diyasporitik boksit cevherleşmesi olduğu saptanmıştır (Şekil 5).

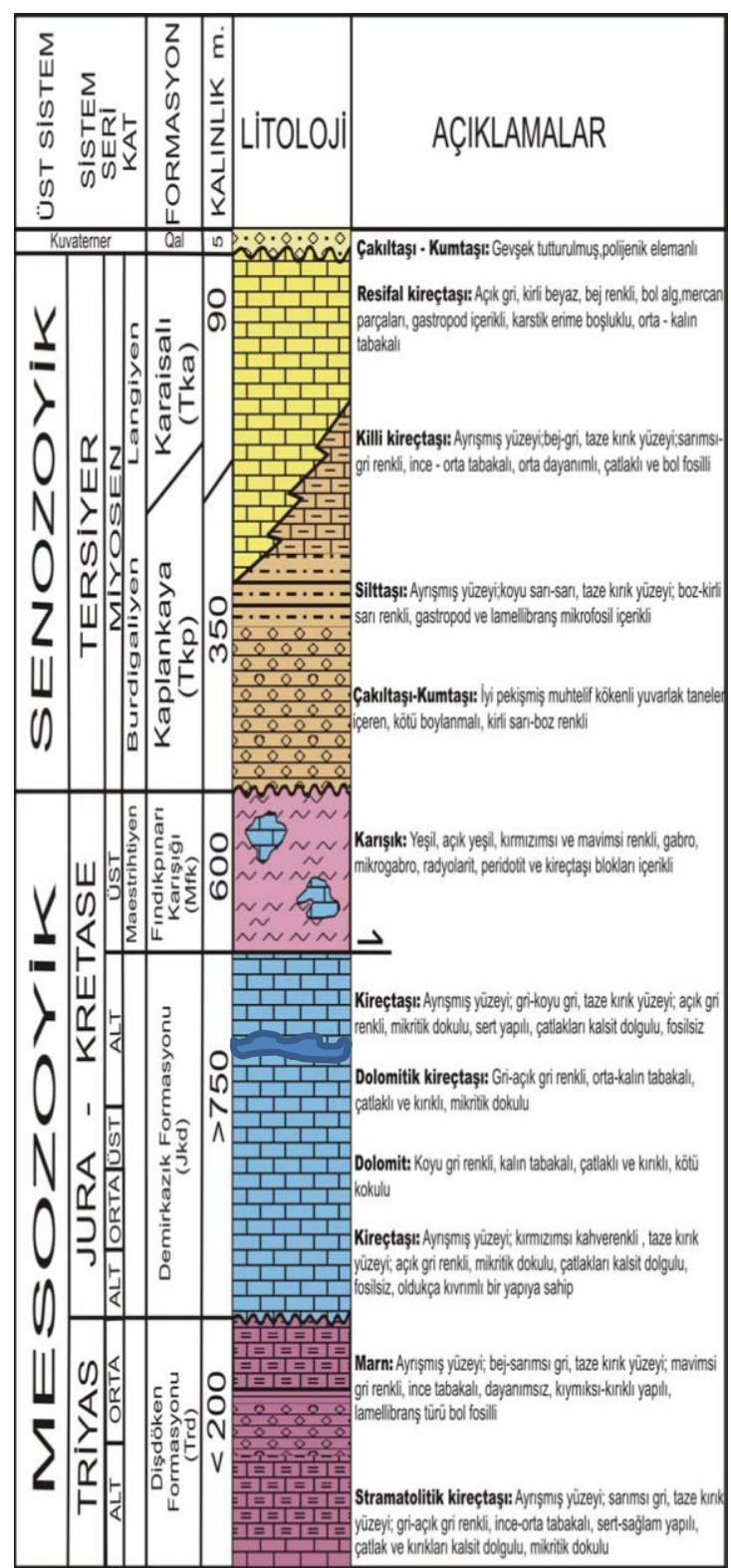

Şekil 2. Çalışma alanına ait düşey kesit [6]

Mikroskop çalışmalarında diyasporit ooidleri, ooidlerin merkezi kesimlerinde veya çeperlerinde limonitleşme ve götitleşme (yer yer lepidokrokit), rutil, hematit mineralleri çoklukla tespit edilmiştir (Şekil 5a). Rutil mineralleri hematitlerin ve ooidlerin merkezi veya çeperlerinde ve yer yer lökoksenleştiği görülmektedir (Şekil 5b). 


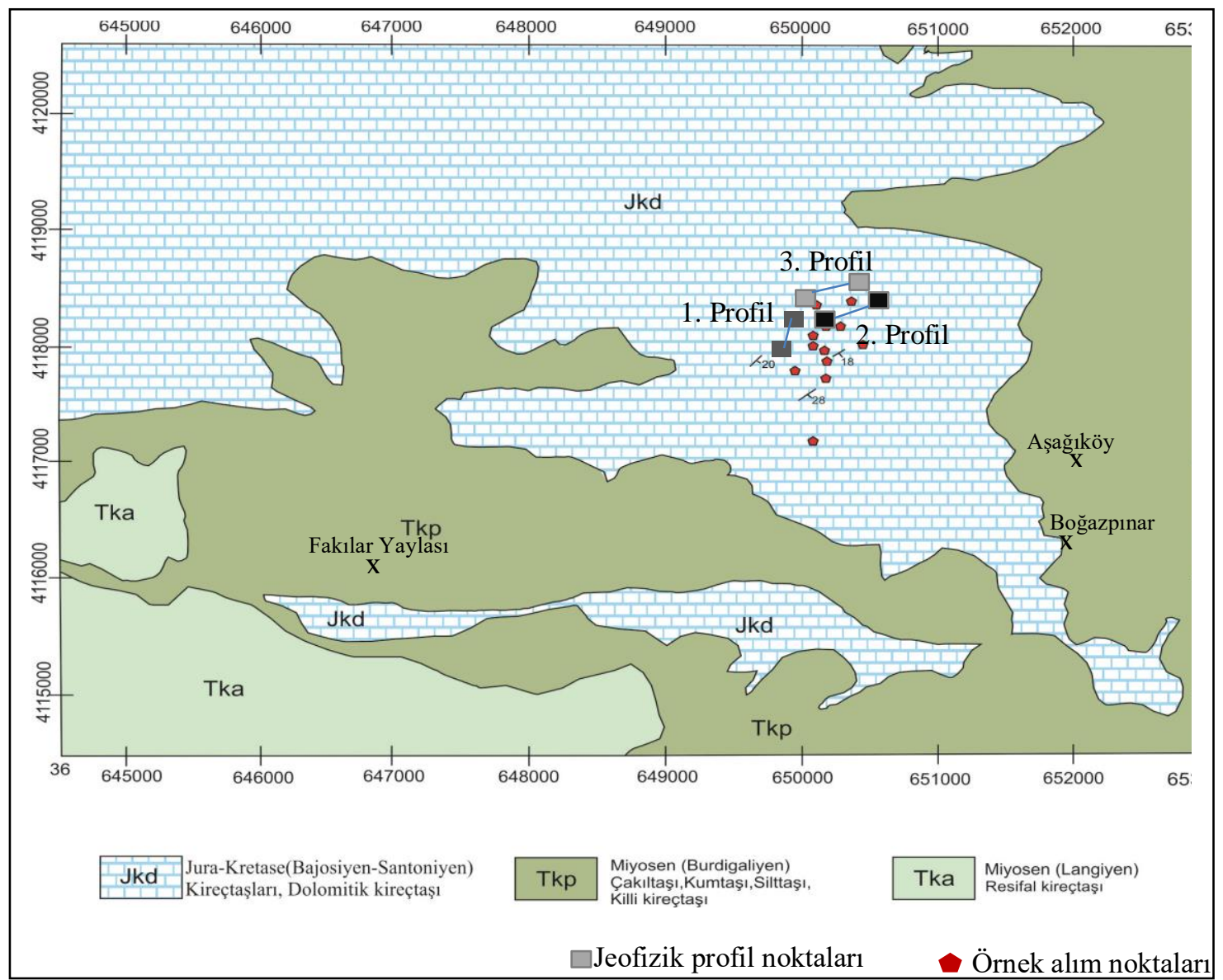

Şekil 3. Çalışma alanı jeoloji haritası [7]

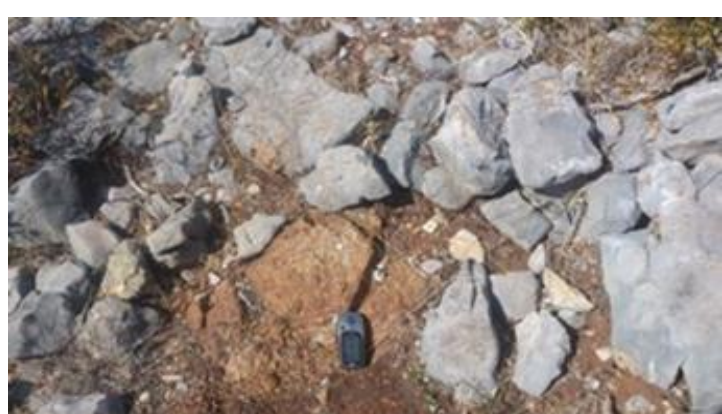

Şekil 4. Kireçtaşları içerisinde pizolitik boksit cevherleşmesi

Hematit ve limonit mineralleri yer yer kırık, çatlak veya boşluk dolgusu şeklinde izlendiği gibi ooidlerin merkezi ve çeperlerinde bulunmaktadır (Şekil 5a,c,d).
XRD difraktometresinde ise diyasporit, hematit, limonit kaolen, rutil başlıca parajezleri oluşturmaktadır (Şekil 6).

\section{CEVHER GEOMETRISI}

Bölgedeki cevherleşmenin geometrik boyutunu tespit etmek amacı ile arazide jeofizik çalışmalar yapılmıştır. Boksit madeni içeriğindeki metalik özellik sebebiyle düşük rezistivite değerine sahiptir. Bu sebeple arazide, AGI marka 8 kanallı 84 elektrotlu cihaz ile Çok Elektrodlu Rezistivite ve IP çalışmaları 3 profilde yapılmıştır. 540 metre uzunluğunda olan profillerde elektrod aralığ1 20 metre alınarak dipole-gradient açılımı kullanılmıştır. 


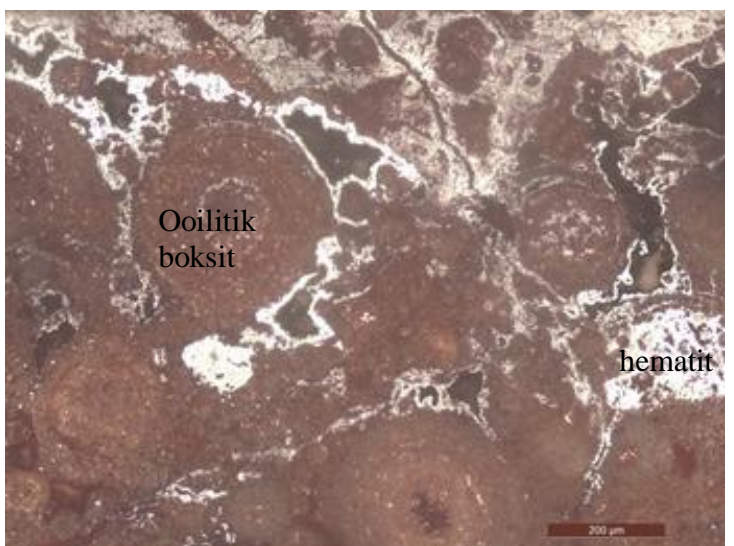

(a)

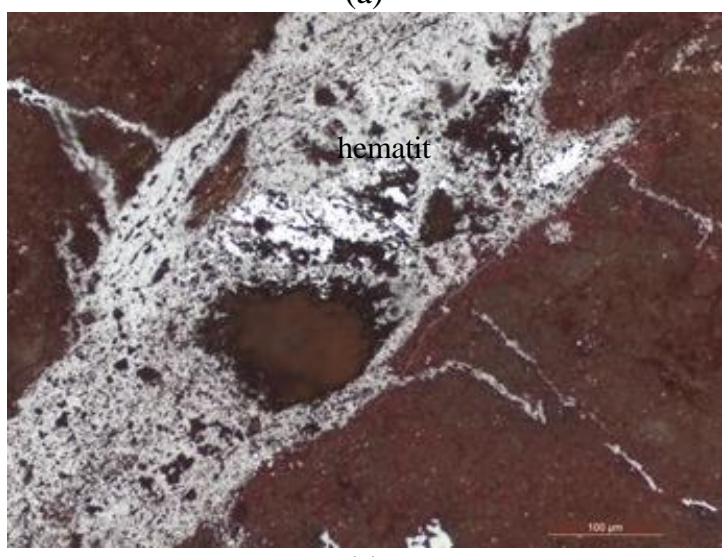

(c)

Şekil 5. Boksit cevherleşmelerine ait mikroskop görüntüleri

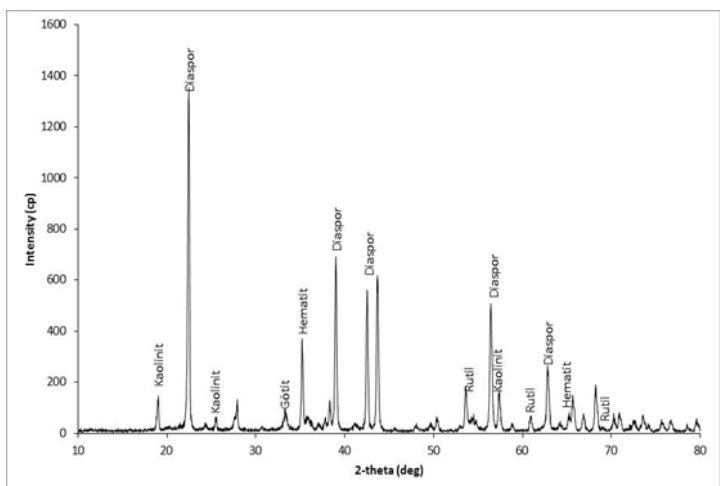

Şekil 6. XRD difraktometre sonucu mineral Analizi

Araziden elde edilen ölçüm verileri 'EartImager $2 \mathrm{~B}$ ve $3 \mathrm{~B}$ ' programında değerlendirilmiş ve yeraltı

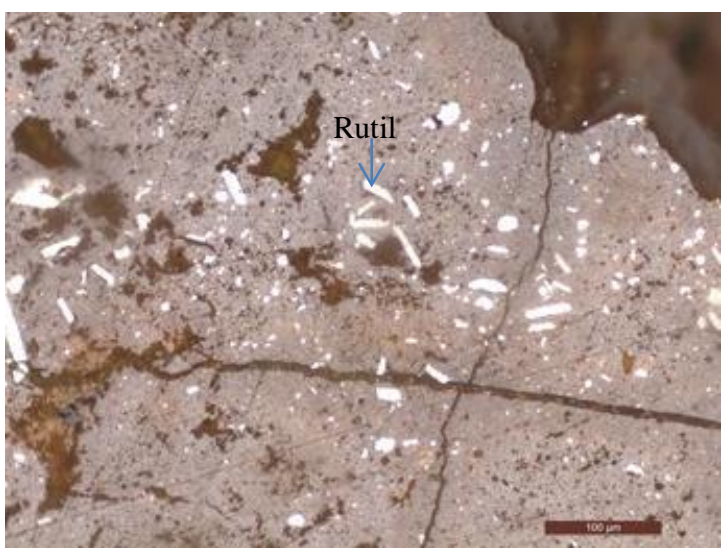

(b)

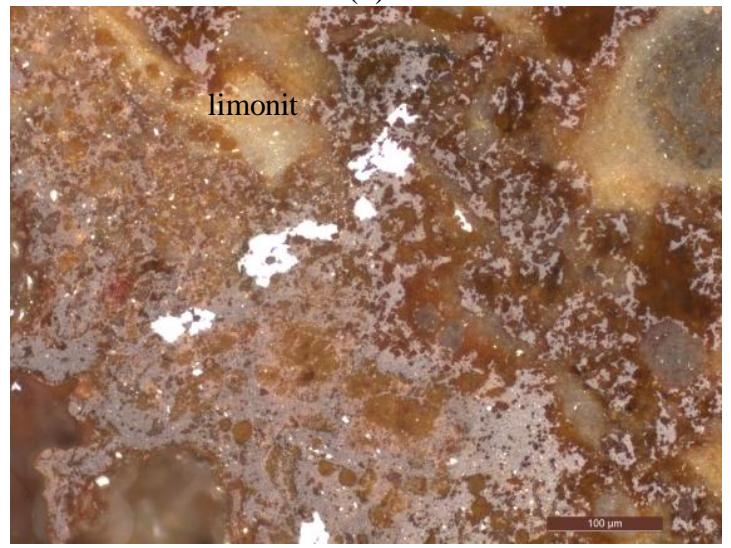

(d)

yapı kesitleri elde edilmiştir.

$\mathrm{Bu}$ kesitlerde Rezistivite ve IP ölçümlerinin birbirlerini desteklediği görülmüştür (Şekil 7). IP kesitlerinde yüksek şarjabilite değerinin elde edilmesi, çalışma sahanında boksit madeninin varlığ1 yönünden olumlu olarak değerlendirilmiştir. Rezistivite kesitlerinde düşük rezistivite değerleri yüzeye yakın alanlarda tespit edilmiştir. Buna göre olası boksit rezervleri, düşük rezistivite ve yüksek şarjıbilite değeri veren yerlerdir. Elde edilen veriler sonucu sadece 3 kesit için ortalama 120.000-150.000 ton'luk bir rezerv söz konusudur (Şekil 8). Bölgenin genelinde ise rezerv miktarının çok daha fazla olduğu tahmin edilmektedir. 


\section{JEOKIMMYA}

Cevher zonlarından alınan örneklerden Kanada Acme laboratuvarlarında ICP/MS yöntemiyle yaptırılan kimyasal analiz işlemlerinde cevher kimyası ortaya konmuştur (Çizelge 2).

Çizelge 2. Cevherlere ait kimyasal analiz sonuçları (ACME lab.)

\begin{tabular}{|c|c|c|c|c|}
\hline Oksitler $(\%)$ & B1 & $\mathrm{B} 2$ & B3 & B4 \\
\hline $\mathrm{SiO}_{2}$ & 1,46 & 8,53 & 3,5 & 6,42 \\
\hline $\mathrm{Al}_{2} \mathrm{O}_{3}$ & 70,04 & 58,87 & 65,6 & 61,78 \\
\hline $\mathrm{Fe}_{2} \mathrm{O}_{3}$ & 10,66 & 15,12 & 13,35 & 14,54 \\
\hline $\mathrm{MgO}$ & 0,07 & 0,33 & 0,14 & 0,26 \\
\hline $\mathrm{CaO}$ & 0,09 & 0,18 & 0,08 & 0,11 \\
\hline $\mathrm{Na}_{2} \mathrm{O}$ & $<0,01$ & 0,02 & $<0,01$ & $<0,01$ \\
\hline $\mathrm{K}_{2} \mathrm{O}$ & $<0,01$ & 0,02 & $<0,01$ & 0,01 \\
\hline $\mathrm{TiO}_{2}$ & 2,87 & 2,44 & 2,63 & 2,48 \\
\hline $\mathrm{P}_{2} \mathrm{O}_{5}$ & 0,05 & 0,03 & 0,03 & 0,04 \\
\hline $\mathrm{MnO}$ & $<0,01$ & 0,01 & $<0,01$ & 0,01 \\
\hline $\mathrm{Cr}_{2} \mathrm{O}_{3}$ & 0,047 & 0,053 & 0,042 & 0,048 \\
\hline LOI & 14,4 & 14,1 & 14,2 & 14,1 \\
\hline Sum \% & 99,74 & 99,74 & 99,572 & 99,798 \\
\hline \multicolumn{5}{|c|}{ Trace elements (ppm) } \\
\hline $\mathrm{Ni}$ & 43 & 314 & 250 & 175 \\
\hline $\mathrm{Sc}$ & 33 & 50 & 38 & 41 \\
\hline $\mathrm{Ba}$ & 19 & 40 & 35 & 27 \\
\hline $\mathrm{Be}$ & 5 & 8 & 7 & 6 \\
\hline $\mathrm{Co}$ & 5 & 14,8 & 11,5 & 9,8 \\
\hline $\mathrm{Cs}$ & $<0,1$ & 1,5 & 1,1 & 1,2 \\
\hline $\mathrm{Ga}$ & 78,7 & 66,1 & 65,8 & 69,7 \\
\hline Hf & 14,7 & 12,4 & 11,8 & 12,9 \\
\hline $\mathrm{Nb}$ & 47,3 & 41,7 & 46,3 & 44,3 \\
\hline $\mathrm{Rb}$ & $<0,1$ & 1,1 & $<0,1$ & 0,9 \\
\hline $\mathrm{Sn}$ & 15 & 11 & 12 & 13 \\
\hline $\mathrm{Sr}$ & 71,9 & 104,1 & 85,2 & 97,3 \\
\hline $\mathrm{Ta}$ & 3,8 & 3,1 & 3,4 & 3,8 \\
\hline Th & 54,6 & 45,2 & 47,6 & 49,3 \\
\hline $\mathrm{U}$ & 9,5 & 6,9 & 6,7 & 7,2 \\
\hline $\mathrm{V}$ & 356 & 253 & 280 & 186 \\
\hline $\mathrm{W}$ & 8,6 & 5,7 & 6,3 & 5,1 \\
\hline $\mathrm{Zr}$ & 504,9 & 441,1 & 398,2 & 456,3 \\
\hline $\mathrm{Y}$ & 61,4 & 61,3 & 61,3 & 60,8 \\
\hline Mo & 3,8 & 1,8 & 2,1 & 3,2 \\
\hline $\mathrm{Cu}$ & 5,5 & 12,7 & 10,9 & 11,3 \\
\hline $\mathrm{Pb}$ & 130,6 & 101,9 & 98,3 & 105,3 \\
\hline $\mathrm{Zn}$ & 61 & 330 & 250 & 185 \\
\hline As & 120,4 & 22,2 & 30,4 & 27,3 \\
\hline $\mathrm{Cd}$ & $<0,1$ & 0,3 & 0,1 & 0,1 \\
\hline $\mathrm{Sb}$ & 11,2 & 0,9 & 1,3 & 5,2 \\
\hline $\mathrm{Bi}$ & 4,8 & 3,1 & 2,7 & 3,5 \\
\hline
\end{tabular}

Çizelge 2'nin devamı

\begin{tabular}{|c|c|c|c|c|}
\hline $\mathrm{Ag}$ & $<0,1$ & $<0,1$ & $<0,1$ & $<0,1$ \\
\hline $\mathrm{Au}$ & 1,3 & $<0.5$ & $<0,5$ & $<0,5$ \\
\hline $\mathrm{Hg}$ & 0,01 & $<0.01$ & $<0,01$ & $<0,01$ \\
\hline $\mathrm{Tl}$ & $<0,1$ & $<0.1$ & $<0,1$ & $<0,1$ \\
\hline $\mathrm{Se}$ & $<0,5$ & $<0,5$ & $<0,5$ & $<0,5$ \\
\hline \multicolumn{5}{|c|}{ Rare earth Elements (REE, ppm) } \\
\hline $\mathrm{La}$ & 117,2 & 87,4 & 92,3 & 120,3 \\
\hline $\mathrm{Ce}$ & 277,1 & 204,3 & 235,3 & 287,4 \\
\hline $\mathrm{Pr}$ & 28,73 & 19,15 & 22,32 & 25,84 \\
\hline $\mathrm{Nd}$ & 106,8 & 65,4 & 78,2 & 82,3 \\
\hline $\mathrm{Sm}$ & 19,90 & 10,10 & 11,3 & 15,6 \\
\hline $\mathrm{Eu}$ & 3,32 & 2,09 & 1,9 & 2,7 \\
\hline $\mathrm{Gd}$ & 12,22 & 9,97 & 10,3 & 11,2 \\
\hline $\mathrm{Tb}$ & 2,01 & 1,80 & 1,87 & 1,92 \\
\hline $\mathrm{Dy}$ & 12,21 & 11,32 & 12,35 & 13,65 \\
\hline $\mathrm{Ho}$ & 2,47 & 2,41 & 1,98 & 2,51 \\
\hline $\mathrm{Er}$ & 8,10 & 7,52 & 7,08 & 7,69 \\
\hline $\mathrm{Tm}$ & 1,30 & 1,18 & 1,09 & 1,25 \\
\hline $\mathrm{Yb}$ & 8,54 & 8,19 & 8,65 & 8,36 \\
\hline $\mathrm{Lu}$ & 1,35 & 1,26 & 1,35 & 1,85 \\
\hline
\end{tabular}

Saha çalışmalarında, yarma yapılarak alınan örnekler, \%70-62 $\quad \mathrm{Al}_{2} \mathrm{O}_{3}, \quad \% 8,53-1,46 \quad \mathrm{SiO}_{2}$, $\% 15,12-10,66 \quad \mathrm{Fe}_{2} \mathrm{O}_{3}, \% 2,87-2,44 \quad \mathrm{TiO}_{2}$ içerikli olarak tespit edilmiştir. İçerikleri bölgenin sektörel anlamda yeterli alüminyum zenginleşmesine sahip olduğunu göstermektedir. $\mathrm{SiO}_{2}$ ve $\mathrm{Fe}_{2} \mathrm{O}_{3}$ değerinin düşük olması zenginleştirme işlemleri için maliyeti azaltıcı etkisi olacaktır. Özellikle tüm sektörler için $\mathrm{SiO}_{2}$ oranının düşük olması istenmektedir (Çizelge 2).

\section{SONUÇLAR}

Fakılar/Mersin bölgesinde yapılan çalışmada elde edilen bulgular aşağıda sunulmaktadır.

- Orta Torosların Bolkardağı bölgesinde yer alan boksit cevherleşmesi, Demirkazık formasyonuna ait Bajosiyen-Santoniyen (Jura-Kretase) yaşlı kireçtaşı-dolomitik kireçtaşları içerisinde yarı düzenli-düzensiz olarak yataklanmıştır. Allateritleşmenin karstik tip modeline uygun kireçtaşları içerisinde bulunan boksitler pizolitik yapıda oluşmuştur.

- Mikroskop çalışmalarında diyosporit ooidleri, ooidlerin merkezi kesimlerinde veya çeperlerinde 


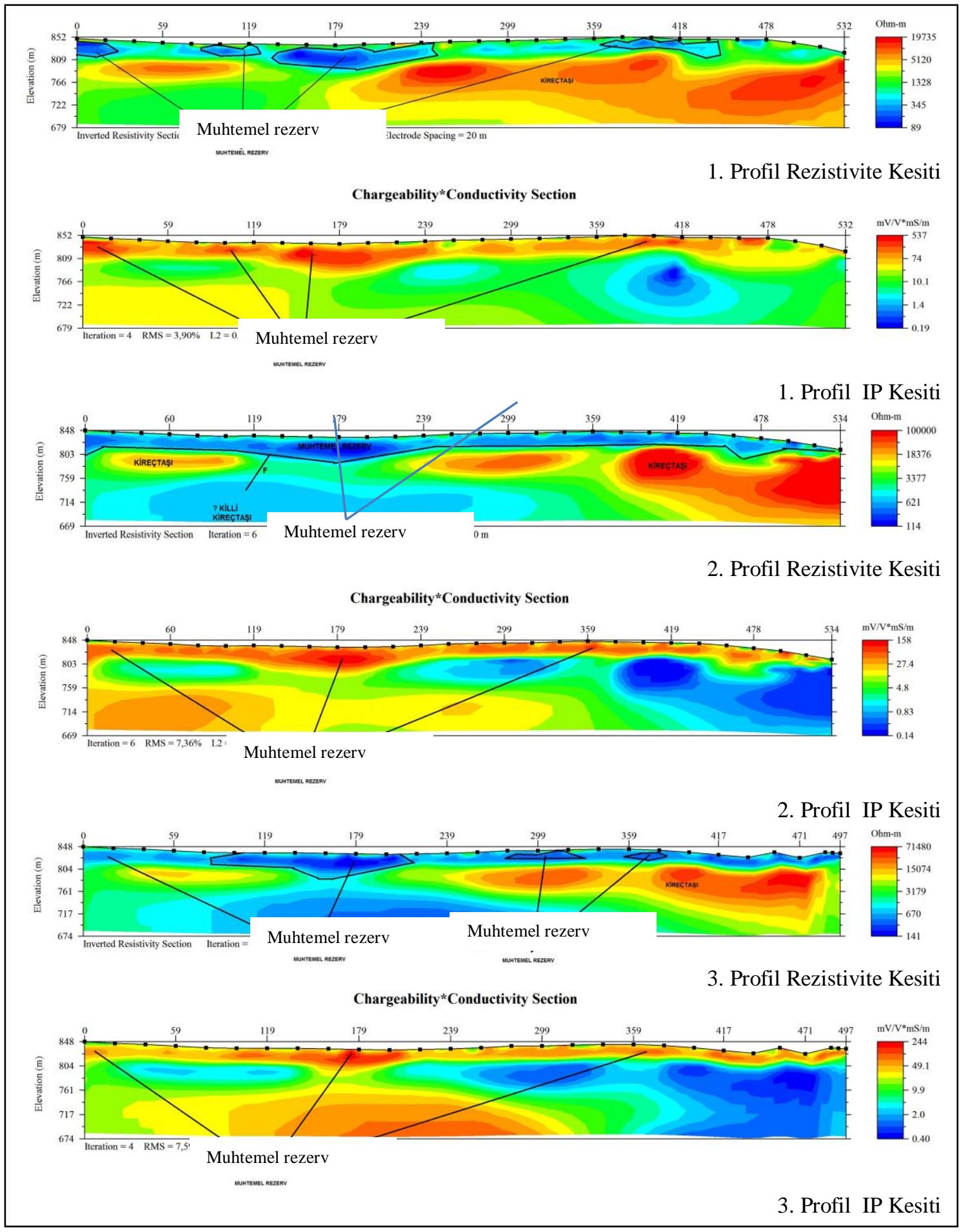

Şekil 7. Profillere ait rezistivite ve IP kesitleri 


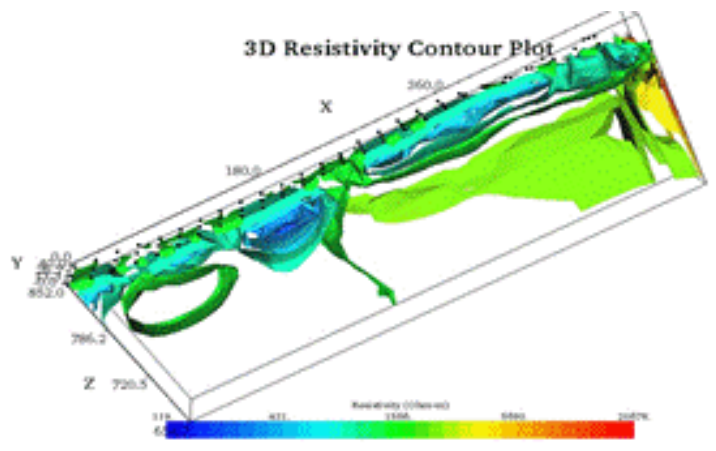

(a)

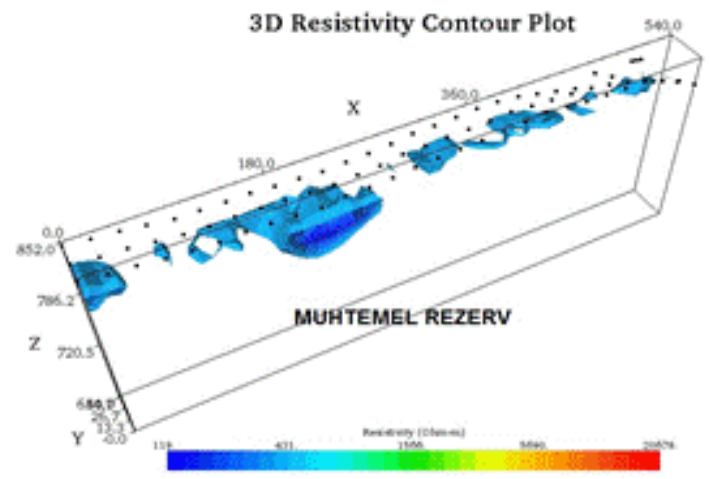

(b)

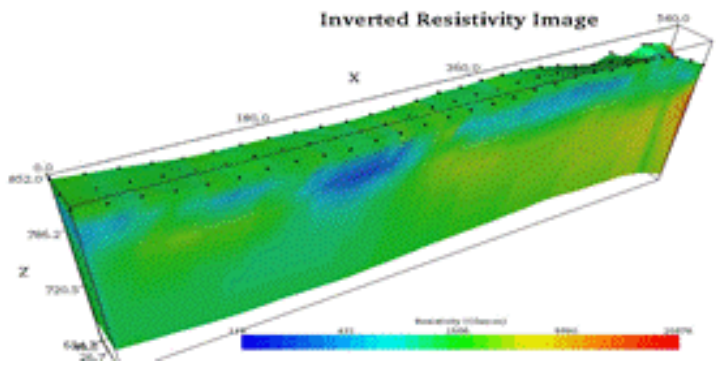

(c)

Y Slices of Inverted Resistivity

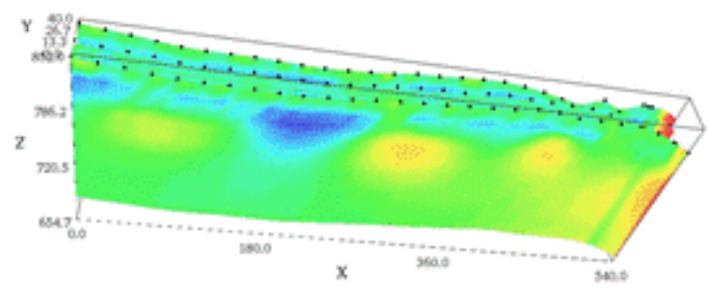

(d)

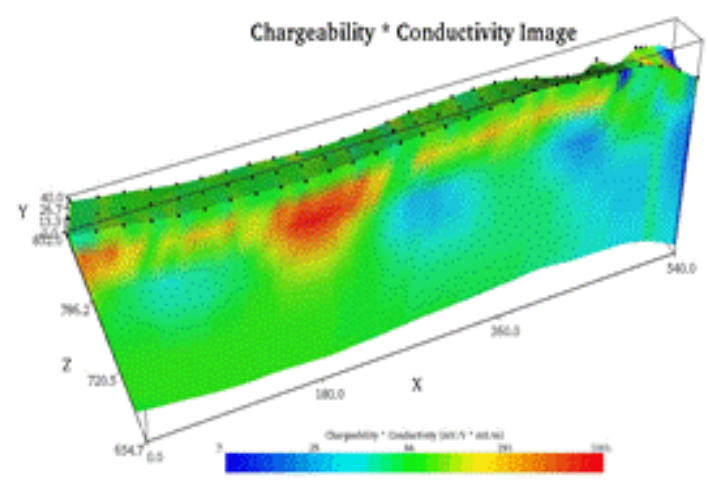

(e)

Şekil 8. 3 boyutlu görüntüleme (a-d) Rezistivite, (e) IP görüntüleme sistemi

limonitleşme ve götitleşme (yer yer lepidokrokit), rutil, hematit mineralleri çoklukla tespit edilmiştir.

- Bölgedeki cevherleşmenin geometrik boyutunu tespit etmek amacı ile arazide jeofizik çalışmalar, AGİ marka 8 kanallı 84 elektrotlu cihaz ile Çok Elektrodlu Rezistivite ve IP çalışmaları 3 profilde yapılmıştır. 540 metre uzunluğunda olan profillerde elektrod aralığ 20 metre alınarak dipole-gradient açılımı kullanılmıştır. Araziden elde edilen ölçüm verileri 'EartImager 2B ve 3B' programında değerlendirilmiş ve yeraltı yapı kesitleri elde edilmiştir. Bu kesitlerde Rezistivite ve IP ölçümlerinin birbirlerini desteklediği görülmüştür. Profillerde 3 boyutlu görüntüleme yöntemi ile cevher geometrisi ortaya konmuştur. Buna göre olası boksit rezervleri, düşük rezistivite ve yüksek şarjıbilite değeri veren yerlerdir. Elde edilen veriler sonucu sadece 3 kesit için ortalama 120.000-150.000 ton'luk bir rezerv söz konusudur. Daha fazla profil analizlerinde bu miktarın çok daha fazla olduğu tahmin edilmektedir.

- Cevher zonlarından alınan örneklerden yaptırılan kimyasal analizlerde ana elementlerden; \%70-62 $\mathrm{Al}_{2} \mathrm{O}_{3}, \% 8,53-1,46 \mathrm{SiO}_{2}, \quad \% 15,12-10,66 \mathrm{Fe}_{2} \mathrm{O}_{3}$, $\% 2,87-2,44 \mathrm{TiO}_{2}$ içerikli olarak tespit edilmiştir. İçerikleri bölgenin sektörel anlamda yeterli alüminyum zenginleşmesine sahip olduğunu göstermektedir. $\mathrm{SiO}_{2}$ ve $\mathrm{Fe}_{2} \mathrm{O}_{3}$ değerinin düşük 
olması özellikle sektörler için istenilen bir özelliktir.

- Cevherleşmenin yüzeyde olması açık işletme yönteminin uygulanabileceğini göstermektedir.

\section{KAYNAKLAR}

1. Madencilik Özel İhtisas Komisyon Raporu, 2001, 8. ci 5 yıllık kalkınma Planı, Ankara.

2. Ünlügenç, Ü. C., 1986. Kızıldağyayla (Adana) Dolayının Jeoloji İncelemesi, Ç.Ü. Fen Bilimleri Enstitüsü, Yüksek Lisans Tezi, $71 \mathrm{~s}$, Adana.

3. Keniş, Ü., 1988. Sarıkavak (Tarsus-İçel) Manyezit Yataklarının Jeolojisi ve Metallojenezi, Ç. Ü. Fen Bilimleri Enstitüsü, Yüksek Lisans Tezi, $58 \mathrm{~s}$, Adana.

4. Ekingen, S., 2003. Çamlıyayla, Mersin Yöresinin Tektono Stratigrafik Özellikleri, Mersin Üniv., Fen Bilimleri Enstitüsü, Yüksek Lisans Tezi, $66 \mathrm{~s}$, Mersin.

5. Yetiş, C., 1978. Çamardı (Niğde) Yakın ve Uzak Dolayının Jeoloji İncelemesi ve Ecemiş Yarılım Kuşağının Maden-Boğaz-Kamışlı Arasındaki Özellikleri, Doktora Tezi, İ.Ü. Fen Fakültesi, 164 s, İstanbul.

6. Kaya, A., 2006. Çamliyayla (Mersin) ve Güneydoğu'sunun Jeolojik ve Tektonik İncelemesi, Yüksek Lisans Tezi, 44 s, Adana.

7. MTA., 2011. Adana-N33 paftas1, Ankara. 